\title{
Link between Higher Education and the Community - a Model
}

\section{Rukhsana Zia*}

\begin{abstract}
Higher Education (HE) in Pakistan presents a case of the "inverted pyramid". The need of the country is to eradicate illiteracy and yet on the eve of the new millenium it stands at a humble 45 per cent. Poverty in the country is on the rise. Given the constraint of the financial resources the downward spiral is evident and yet the masses at the grassroots level could greatly benefit from increased literacy skills. Equipping them with functional literacy skills would clearly improve their quality of life. Given the two opposing trends whereby the country needs to provide massive literacy skills to its populace and the infrastructure of education heavily biased in favour of $\mathrm{HE}$, an innovative approach within the education system and its mode of delivery is needed. This paper focuses on one such possibility and proposes a model to develop a link between the two to place the benefits of $\mathrm{HE}$ at the doorstep of the populace where it is desperately needed.
\end{abstract}

\section{Introduction}

The idea is not original. Land-Grant higher education (HE) institutions, colleges and universities were established in the USA in 1862, basically to provide education to the members of the working class. It was meant to make HE accessible to the common man with the added benefit of an education that was relevant to their everyday life and to date these $\mathrm{HE}$ institutions continue to fulfill their democratic mandate for openness, accessibility, and service to the people (NASULGC $1995 \mathrm{p} \mathrm{4).} \mathrm{But} \mathrm{these} \mathrm{HE}$ institutions had to modify their modus operandi with the changing times and changing needs. In the early twentieth century, it was found that the land-grant colleges and universities established for the common man / woman, were finding it increasingly difficult to meet their legislative mandate to disseminate research-based $\mathrm{HE}$ information to the general populace / rural residents (O'Neill and Wood 1989 p 38). A better way was sought to bring information to the people who needed it (Waller 1958). When placed in an historical perspective it is easy to see that the USA then was predominantly rural in character. With vast open spaces and scattered population, it was difficult to educate the masses. The arrangement of local

\footnotetext{
* The author has a Ph.D. in Education from the University of Wales and is an Associate Professor at the College of Home Economics, Lahore.
} 
programmes from distant universities and colleges was a drain on the resources and logistically difficult to manage. In 1914, the Smith-Lever Act was passed in the USA and soon after, the Congress established the Cooperative Extension Service. It was essentially cooperation between the Departments of Agriculture and Home Economics- the two departments of $\mathrm{HE}$ institutions- found to be relevant to the needs of the majority of the populace. It was an innovative form of education, one in essence designed to reach the field / the grassroots level. Though the population was largely literate it was still impossible to reach a large number of people through written / printed materials. It was decided then that extension workers of the Cooperation Extension Service be sent to the community to interact with the masses in the field. The fundamental idea was to offer an opportunity for education, related to the practical realities of life, to a larger number of the population. Educational programmes were developed according to the needs that existed at the community level and with time, these evolved with the changes in technology. More importantly, Extension Services acted as a change-agent to prepare people to the latest possible changes and expected challenges. With such a dynamic existence it is only to be expected that the future of agents / workers who coordinate $\mathrm{HE}$ and the community will be full of challenges. And as the communication processes and technology become increasingly advanced their challenges will become more daunting and imaginative.

In relating the above to the scenario in most developing countries such as Pakistan, several parallels are immediately evident. On another level though, the discrepancies are also highlighted. Pakistan is a predominantly rural community (66 per cent) with a considerable urban slum. A large segment of the population is illiterate and exists in conditions of extreme depravity. The Human Development Indicators (HDI) are even more pathetic, i.e. 0.383 (UNDP $1996 \mathrm{p}$ 139). The HDI factors in rural areas are lower still, and within these the rural woman is the worst hit and exists in a state of utter neglect ( $\mathrm{Zia} 1998 \mathrm{p}$ 23). When placed in an holistic perspective, it is clear that the need of the time is to provide education and skills to the rural woman whereby she can improve her quality of life and be empowered to take on economic responsibilities. The extension / outreach programme, as it is known in the USA, is poised to offer a variety of information at unconventional hours to unconventional clients in unconventional packages (O'Neill and Wood $1981 \mathrm{p}$ 40). And this is exactly what such a programme has the potential to offer in a country such as Pakistan. It is for this reason that it has been propounded as a model ideally suited to developing nations, i.e. those with limited resources so that they can be propelled to a greater state of self-sufficiency (Belck 1985 p 46). 


\section{The Proposed Model}

In November 1998, the Department of Social Welfare, Women Development and Bait-ul-Mal Punjab, organised a provincial workshop on "Strategy Planning and National Plan of Action for Women Development". One of the working sub-groups on Education, of which I was also a member, made a recommendation of linking HE institutions to the rural community. At the time it was established Pakistan projected a case of "Inverted pyramid" with a narrow primary education base and a wide HE top (Zia $1994 \mathrm{p} \mathrm{10),} \mathrm{when} \mathrm{it} \mathrm{should} \mathrm{have} \mathrm{been} \mathrm{the} \mathrm{other} \mathrm{way} \mathrm{round.} \mathrm{It}$ was also recommended that the expertise of $\mathrm{HE}$ institutions, as a structure that was already in place, be utilised for the benefit of the populace. It was proposed that HE be linked to the rural areas (since $\mathrm{HE}$ as a service is non-existent in the rural areas)/ community wherever applicable. It was also proposed that the government make this mandatory, as this would ensure that the massive $\mathrm{HE}$ infrastructure was not left for the benefit of the privileged few. Another vibrant theme of this workshop was the proposal to establish links between various sectors/departments/ organisations of the country. As a direct result of the above suggestions one such model is proposed for a link between $\mathrm{HE}$ and the underprivileged community. This model has the added advantage of emphasising partnership/networking between governmental and non-governmental organisations, in this case, Government College of Home Economics (CHE) Lahore and BUNYAD Literacy Community Council (BLCC), a nongovernmental organisation (NGO). A link will be established between these two for the benefit and welfare of the under privileged female (directly) and the community (indirectly), be it in a rural area or an urban slum. Pakistan is an agriculture-based economy. Like other developing / under developed economies of the world, it exhibits traits of high illiteracy, high population growth, malnutrition, migration from rural to urban areas resulting in urban slums, high unemployment rates and so on (UNDP 1996). Constraints of the financial resources demand that these be utilised to the maximum with the minimum of wastage. The national development programmes should focus on the real and personal needs of the urban and rural poor (the majority of the country's population). These translate to need for improved housing, better nutrition, improved food / dietary practices to maximise the usage of available food, and appropriate skills to maximise the potential of agricultural land, and so on. Learning everyday life / practical skills is an essential need for the populace in developing themselves.

Home Economics in Pakistan is a purely female discipline (in other countries of the world the discipline attracts a strong male clientele as well. In most countries of the world the discipline is now named as "Family and 
Consumer Sciences". The purpose is to advance the well being of the families focusing on their roles as consumers of goods and services, providers of services and producers of goods. CFCS 1998 p 1-2). The five main subject areas of the discipline in CHE are Food and Nutrition; Clothing and Textiles; Human Development; Housing and Home Management and Related Arts. Apart from the above core areas there are supporting subjects such as physical sciences, languages, economics, statistics, religious studies and computer studies. It is evident that Home Economics is a distinct professional field and basically focuses on imparting knowledge, skills and attitudes that are crucial to improving the quality of life of the individual and the family. It is also worth noting that the success of the market economy is attributable in large part to the existence of a strong non-market institutions such as the family, which has been the primary agent of socialisation and, in conjunction with religion, the primary source of values (Fuchs 1983 pp. 240-241). The author is commenting on the American way of life, but it is applicable to Pakistan as well. Placed in the above perspective, it is clear that the discipline provides human resources and information that are crucial in addressing the social and economic problems of the country. Strategically speaking, linking quality of life and family is a sound and effective social technique and these strategies can help frame quality of life issues in ways that are consistent with many of society's accepted values (CFCS 1998 p 4). Hence, the case for taking Home Economics to the underprivileged community makes sense in light of the fact that what it offers is relevant to the needs of the masses that have limited resources (and within that the most deprived, the female).

BLCC is very active in the province of Punjab. It has the largest number of Literacy Centres. Since its inception in 1992 to date, it has made a tremendous impact in promoting literacy in the rural communities of the Punjab. It has at present over 700 centres in 11 districts. The centres are organised with the help of the community, who contribute in kind by offering space / room / building and utility bills for the centre. The teacher is selected from the community with the minimum qualification of matriculation / or ten years of schooling, and then groomed with continuous in-service training and education. The mode of delivery of education is by the non-formal system. The learners are provided education according to the government curriculum for primary grades and recommended textbooks of the Punjab Textbook Board are used as instruction material.

The operational details regarding the model are outlined in the following paragraphs. The $\mathrm{CHE}$ intends to initiate a Community Development Unit (CDU) with the explicit aim of reaching out to the community for an improved quality of life. The access to the community 
will be managed through the existing infrastructure of BLCC. The following procedures will be initiated to process the model:

- A community will be identified for the project-consideration will be given to the community that has a BLCC literacy centre;

- CHE will formulate effective procedures / research tools for needassessment of the community;

- Need-assessment will be carried out by the master-trainers / teachers of BLCC literacy centres, who will be trained by the CDU staff to use these tools;

- The results of the survey will be sent to the CDU where it will be collated and analysed by the CDU staff;

- On the basis of the assessed and prioritised needs (of the community), instructional materials and / or skills will be designed and developed;

- The master trainers of BLCC will be trained by the CDU staff to deliver the prepared instructional materials / skills to the teachers of the literacy centres;

- The teachers will deliver the prepared materials and / or developed skills to the learners;

- The programme will be periodically evaluated to monitor and improve its efficacy, impact and effectiveness.

CHE will thus reach out to underprivileged females and families with accurate, research-based information according to the specified needs of the community. This will equip them with knowledge / awareness of possible options open to them. By linking the expertise of $\mathrm{CHE}$ with the rural / underprivileged community via BLCC (the vehicle for outreach programme implementation), the establishment of a new infrastructure will be avoided. BLCC with its amazing success story and credibility in the rural I underprivileged areas will be instrumental in fostering strong and beneficial links wherever required and necessary.

The figure below, very simplistically states the networking of the CHE and BLCC to provide appropriate services to the community as per the objectives of the CDU.

Figure-1: Diagrammatic Representation of the Model 


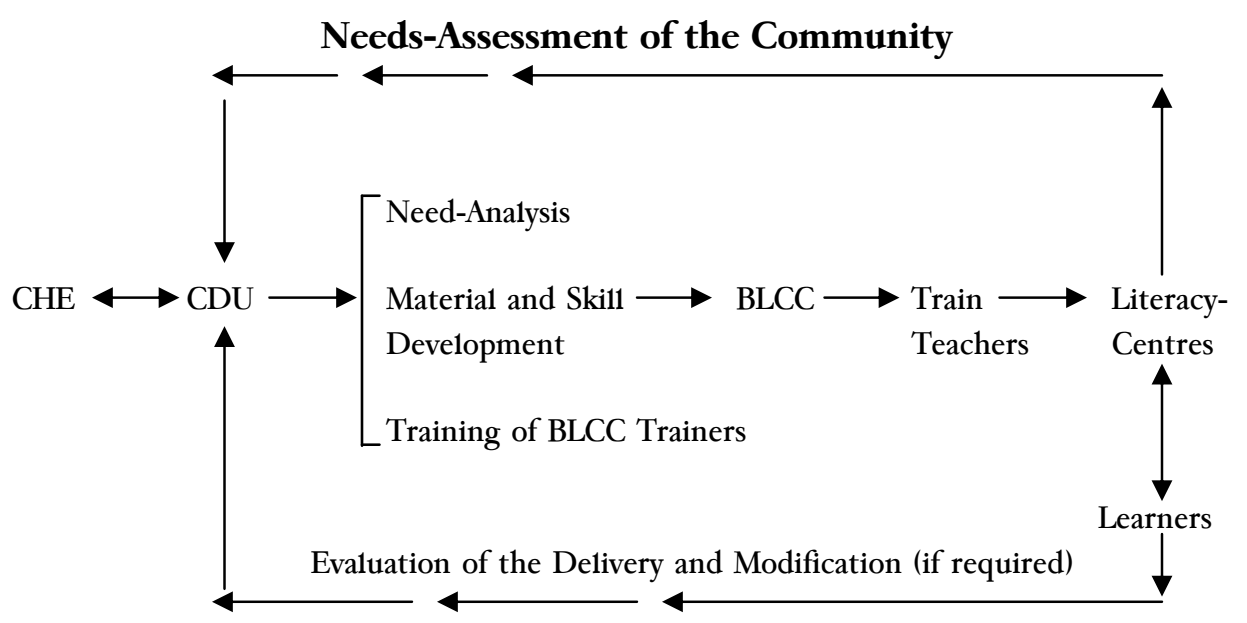

This model will be extremely beneficial, and some impact possibilities are stated below:

\section{Improved Quality of Life and Poverty Alleviation}

The ultimate aim will be to develop a sustainable connection between CHE and the community, an outreach link to anticipate opportunities that will contribute to an improved quality of life and a better future for the deprived communities. Effective strategies will be devised to impart knowledge and skills to the community, so that even within the same resources there will be a tangible improvement in the quality of life of the rural woman and the family. This could be in terms of better health and nutrition; improved hygiene; better childcare; cleaner environment, to name a few. Improvement in skills would lead to increased employment, smallscale enterprise and income generating opportunities for the community. All this will alleviate the poverty and suffering of such families and make the community a better place to live and work.

\section{Better Education}

It will help develop outreach educational activities between the $\mathrm{CHE}$ and poorer communities in the Punjab. Through appropriate mechanisms, educational expertise and resources of the CHE will be transferred to the targeted rural / underprivileged communities. This will provide knowledge, skills and opportunities to the poor to participate in educational programmes in keeping with their identified needs. It is anticipated that educational outreach activities will have many benefits. For example, this will help community groups recognise their assets, identify their opportunities and be better able to devise strategies for their future. 


\section{Strengthening of the Participating HE Institution and the NGO}

The establishment of CDU will strengthen the existing infrastructure of CHE. A sustainable process of faculty development will have to be maintained to keep the CDU operational according to its specified objectives. Research possibilities in the area of community intervention will be endless with a strong focus on its dissemination. The projects undertaken and the ensuing research will be live and real, with immense possibilities for generalisability to similar communities. In addition, $\mathrm{CHE}$ and its associated faculties will benefit as an institution through the development of collaborative research, curriculum development, new courses and teaching materials which will be more clearly focused to the needs of Pakistan as a whole. The institution will benefit from management development systems established as part of the new CDU. This will simultaneously strengthen the NGO itself. The teachers will benefit with the training provided, the literacy programme will be more related to the needs of the learners, and programme delivery will be more appropriate and effective.

\section{Partnerships between Different Organisations}

This model represents a unique and innovative collaboration between the CHE Lahore (an HE institution) and a national NGO working in the Punjab BUNYAD, a case of effective networking between the governmental and non-governmental institutions. At the operational level, CHE will link with BLCC and its partners (other Community Based Organisations) to develop outreach programmes for the implementation of educational activities and materials. This unique relationship will bring together a range of experience and expertise, which will have an impact on the quality of higher education in Pakistan, simultaneously strengthen NGO programme delivery and ultimately improve the lives of women and communities at the field level.

\section{Conclusion}

The above stated model offers a highly innovative management approach. It is cognisant with the needs of the developing economy and more importantly, exploits the existing HE structures for the optimal benefit of the country as a whole. It is proposed that this model be seriously considered by all $\mathrm{HE}$ institutions as one possibility in response to the structural and procedural changes so urgently demanded by the contextual features of our country. 


\section{References}

Belck, N., 1985. Delivering Home Economics Information to families in developing nations: building on the extension mode1, Journal of Home Economics 77, 4, 46-48.

College of Family and Consumer Sciences, 1998. AAFCS Self-Study 1998: Iowa State University. Ames: CFCS.

Fuchs, V.R., 1983. How We Live: An Economic Perspective on Americans from Birth to Death. Cambridge: Harvard University Press.

National Association of State Universities and Land-Grand Colleges, 1995. The Land-Grant Tradition. Washington: NASULGC.

O'Neill, B.M. and Wood, R.T., 1989. Extension Home Economics: past, present and future, Journal of Home Economics 81, 3, 38-40.

Tate, M.T., 1961. Home Economics as a Profession. New York: McGraw-Hill Book Company.

United Nations Development Program, 1996. Human Development Report 1996. New York: Oxford University Press.

Waller, I., 1958. Where There is Vision: The New Jersey Agricultural Experiment Station 1880-1930. N.J: NJ Agricultural Experiment Station.

Zia, R., 1994. A study to investigate the requirements of a continuing professional development programme for the higher education academic staff, Punjab, Pakistan. An Unpublished Doctoral Thesis submitted to the University of Wales, U.K.

Zia, R., 1998. Profile of the Rural Woman of Pakistan, in The Labore Journal of Economics, 3, 1. 